Krokinskaya O. K. Okladnikova E. A.

\section{«BOOKS AND PEOPLE»: RESULTS OF THE PUBLIC POLLS ON READING PROBLEMS AT THE ST PETERSBURG INTERNATIONAL BOOK FAIR 2015}

1) Doctor of Sociology, Professor. Herzen University. 48 Moika, St. Petersburg, 191186, Russia. E-mail: krokinskaya@mail.ru 2) Doctor of Historical Sciences, Professor. Herzen University. 48 Moika, St. Petersburg, 191186, Russia.

E-mail: okladnikova-ea@yandex.ru

\begin{abstract}
.
The purpose of this article is to present the results of sociological research on a number of issues of modern reader practices that develop a deep and a substantial impact of reading on the inner world of a reader. The survey audience is the visitors of the Tenth International Book Fair, held in St. Petersburg in May 2015. The present study was carried out using the questionnaires and formal interviews, and the processing of empirical material was carried out by case-study method. Despite the fact that the survey sample can not be regarded as a strict one, we tend to consider the results of the study as the representative ones. The obtained statistics allowed to bring the data together and carry out their analysis as a whole, though the analysis of respondent answers proved to be more informative one and distributed by age groups. During the survey we were able to identify the great interest of respondents to foreign literature, the decline of interest in poetry, an expressed separation of reading public into interest groups. Book Salon-2015 visitors tend to respect an ambiguous character of novels, choose a variety of literature and showed a great interest in developing, meaningful reading.
\end{abstract}

Key words: reading; Book Salon 2015; sociological survey; the effect of reading; modern readers.

Крокинская О. К. Окладникова Е. А.
«КНИГИ И ЛЮДИ»: РЕЗУЛЬТАТЫ СОЦИОЛОГИЧЕСКОГО ОПРОСА ПО ПРОБЛЕМЕ ЧТЕНИЯ НА САНКТ-ПЕТЕРБУРГСКОМ МЕЖДУНАРОДНОМ КНИЖНОМ САЛОНЕ 2015 ГОДА
In May 2015 the Tenth International Book Fair took place in St. Petersburg. According to organizers, the Salon was visited by over 200 thousand people with St. Petersburg citizens and the guests of the city. The salon operation was performed by the representatives of 20 countries and 14 Russian regions, their museums, libraries, book-selling companies and educational institutions. The Russian State Pedagogical University named after A.I. Herzen (Herzen University) also took part in it. With the help and the support of St. Petersburg library society and the Library named after V.V. Mayakovsky the students of the Department of sociology at the Faculty of Social Sciences (Herzen University) conducted a sociological survey concerning the following topic: «Books that changed us». The study was led by the doctor of sociological sciences, the professor of sociology department (Herzen University) Olga Konstantinovna Krokinskaya and the doctor of historical sciences, the professor of sociology department (Herzen University) Elena Alekseevna Okladnikova. The co-authors of the project were 3rd year students (in May 2015), Ekaterina Avkhimovich and Irina Smirnova. The survey was also performed by Christina Zhukova. The survey was conducted using questionnaire method, the questionnaire is the product of joint work among co-authors.

Before we present the results of the project, it is necessary to determine the limits of its cognitive capacities. According to content volume and the number of respondents it was a small work, but it contained the questions, which were rarely included in the zone of large project interest.

The overall picture of reading in Russia was fundamentally studied by the Levada Center team of authors a few years ago [4]. The materials of this research are often published under the title "Catastrophe of reading» that is were evaluated as an indication of a serious social and cultural problem. Its main features were:

- the reduction of constant share of newspaper, magazine and book readers in particular (the proportion of adult Russians who do not read books, approached to $50 \%$ );

- the change of reading content: the shift of interest from high genres of fiction to a mass fiction 
genre (detective, action novel, love prose, historical and adventure novel);

- the dominance of TV viewing and entertainment genres over reading, the development of tastes by mass serial genres;

- the change of access structure to quality literature, the decline of libraries, the lack of expert advice;

- a controversial Internet influence on reading with positive and negative effects.

In general social sense this could entail, and entailed today the cultural separation and the split of macrosociety, the reduction of intellectual demands, the loss of values (cultural, moral ones), the guidelines and the immersion into antisocial nature, and along with other incentives of situation - the distortion of cultural reproduction institutions, the decrease of education quality, etc.

However, it is impossible to ignore the presence of advanced, modern-oriented groups and population strata in society, including children and young people, - the fact that does not allow to picture the studied phenomenon exclusively by black and gray colors. People read. And the work of St. Petersburg salon, Moscow Book Festival and others, including the regional book forums showed that they attract a large number of interested participators, and therefore, books and reading did not disappear from the range of our citizen cultural needs. These positive facts should be examined at least as closely as the negative ones. Without them, the picture of reading in Russia will be incomplete and unreliable.

In our project, the Book salon operation made it possible to refer to the audience opinion, usually dissolved in mass surveys - to book fans, the people with a distinct focus on reading, the bearers of book culture values, whose lifestyle includes active reading practices. Against the background of a mass object, which is studied by large research centers, it was a spot metering, made in rare circumstances. The statement of the problem task made it possible to look into the area of direct influence of literature, books and reading on the development of life and an inner world of a reader.

In the context of lack of time and resources our project was carried out by face to face survey method, using questionnaires (in the formal interview mode), which, however, did not exclude the possibility for respondents to comment their answers, which partly made up the lack of a deeper theme study by qualitative methods. We consider it necessary to warn that the survey sample can not be considered very strict. The interviewers talked with the salon visitors who put aside their personal intentions for some time and agreed to answer the questions. Therefore, the study results are not referred as representative ones, and its status shall be determined as the case analysis. In the cases when statistical indicators allow to combine the data they are analyzed as a whole, but the analysis by age groups proved to be a more informative one.

Sampling characteristic and survey situations. The situation of a survey created difficult conditions for the search of respondents. The search took place in a huge building of the former horse arena as large as a good stadium, which had «Brownian» streams of visitors along «book alleys». We are grateful to all those who agreed to answer our questionnaire and, therefore, developed a custom set of «available cases». By occupation the sample included mostly highly qualified experts of different fields of activity - university professors, teachers, doctors, engineers, scientists, managers, journalists, writers, librarians, the representatives of creative professions (artists and designers), as well as the professionals of book publishing and editors. The total amount of interviewed made 116 men, including $79 \%$ of women and $21 \%$ of men. Approximately two thirds of respondents were the residents of St. Petersburg, and one third was represented by the guests of the city. The age range made $13-75$ years, with the predominance of young adults (18-35 years $-56 \%)$. The majority of respondents have a higher education and a degree (53\% and $3 \%$, respectively), the persons with vocational education (technical school, college) amounted to $10 \%$, while students and pupils made $14 \%$ and $18 \%$ respectively. Then the following results of the study are presented.

General reading contexts. What do reading fans and book experts who came to the Book Salon love to read? Their preferences vary and depend on age (Fig. 1). Teens expectedly choose mainly adventure and science fiction (79\% and $71 \%$ of responses respectively). Only teens read comic books (29\%) and a small proportion of them (14\% for each type) prefer love stories, thrillers and detective stories, science and scientific-popular literature. 


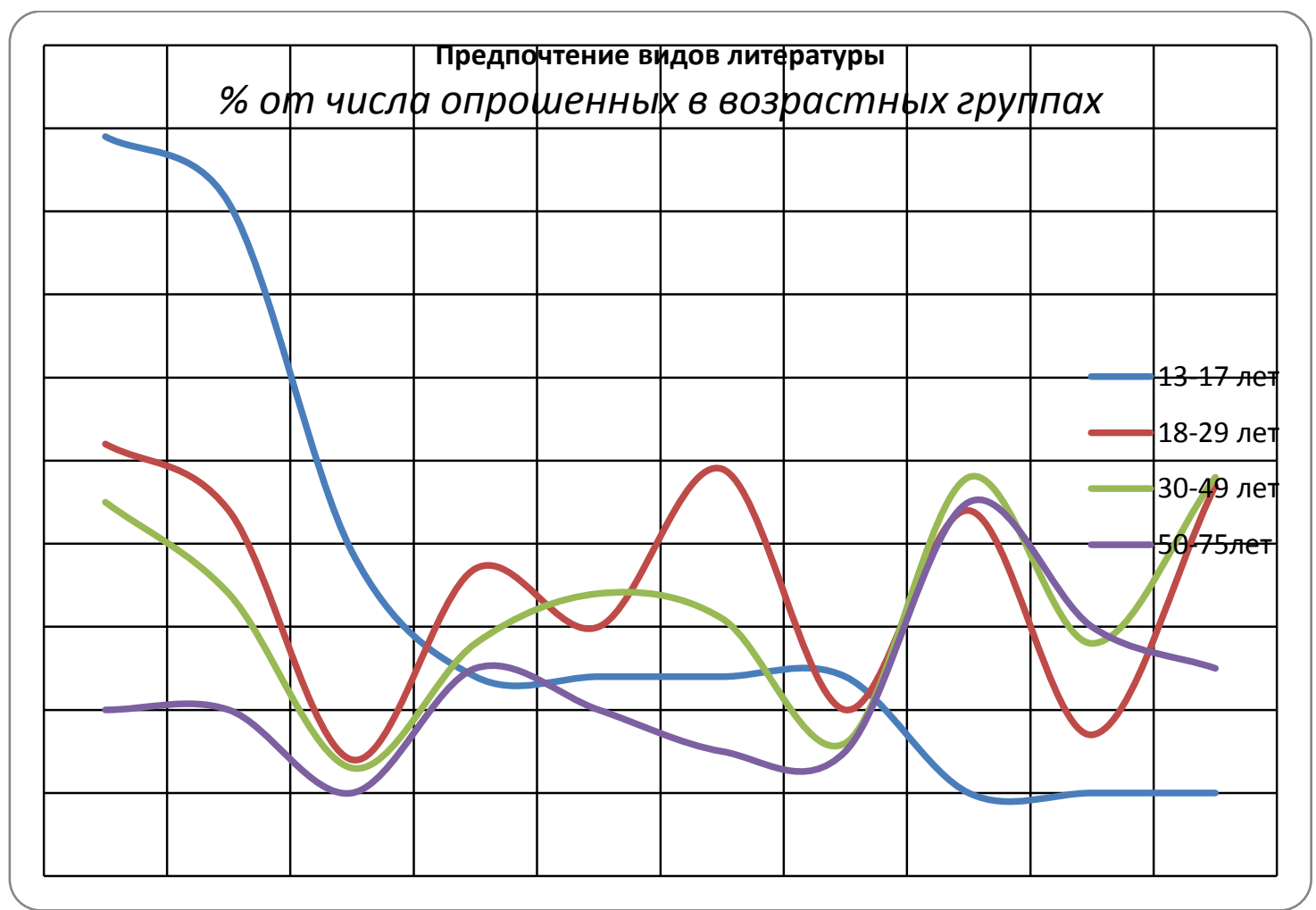

Literature preferences \% from the amount of interviewed in age groups

Adventure stories, fantasy, mystery, comics, love novels, scientific literature, science-fiction, thrillers, detective stories, historical novels, memoirs, the biographies of famous people

Fig. 1.The dependence of reading preferences on the age of respondents

Young people (18-29 years) and an average adult group (30-49 years) have the widest range of reader interests. They are also like teenage literature (adventure, fantasy, mysticism), but the share of their supporters is gradually reduced, decreasing to $25-$ $35 \%$. But the status in the structure of reading is increased by scientific and popular scientific literature, as well as by historical novels and biographies (the range of responses makes about 20$40 \%$ ). Suddenly the narrow profile of reading was demonstrated by the older age group. With the interests around historical works, memoirs and biographical literature $(35 \%-15 \%$, respectively), the group looks very conservative one. However, the respondents of this age group often added (more often than other groups) that they enjoy the reading of all genres from the proposed list, that is they do not have any preferences actually.

The picture of literary preferences is complemented by the interests of interviewed in the field of literary genres of prose and poetry, domestic and foreign one. These interests are expressed quite clearly. The priority belongs to Russian literature, especially to its classical forms (36-39\%), while foreign classics, prose and poetry attracts $17-29 \%$ of the respondents. But the position of Russian literature can not be called an absolutely dominant one. Foreign Prose scores points by preference gradations concerning contemporary works $(19 \%)$ and an equal acceptability of classical and modern works (43\%). Due to these positions the share of domestic and foreign literature presence in the reading of the respondents is almost the same one. A relatively lower interest is fixed in relation to poetry. $13 \%$ of respondents are not interested in national poetry and $25 \%$ of respondents are not interested in foreign poetry. We will see the illustrations of these facts in other research materials.

Reader's expectations. Why do people read? What do they expect from the dialogue with a book? In general, people read for pleasure - an intellectual, an aesthetic and an emotional one; in order to fill leisure time, to sit in an arm-chair, to have a rest, to relax; for the sake of entertainment and the distraction from reality; to pass some inevitable routine, boring, empty periods, like everyday driving to work during one - two hours or even longer; people also read for the sake of knowledge, because of interest, to learn something new and useful, to answer the disturbing questions about yourself, family, children, country, etc. 
Today, many authors pragmatically focus their works to these requests. Others simply create, and their work creates a lot of situations not foreseen in advance. A reader reads for pleasure, and in the meantime some kind of values, ideas, puzzles, challenges, knowledge, behavior, philosophy models are given to them, etc. He accidentally takes the first available book from a shelf for recreation, and then looks at the cover and looks for an author's name, to praise or stigmatize him. And over time a reader has certain expectations from reading, he learns to judge reading in order to continue it and its place in culture. That's why we may ask such a reader about his assessment of a book as a companion and as a mentor.

Value expectations of readers. When they asked whether a book should translate some values or ideas an unequivocal answer was given. Yes, it should. This view is clearly expressed in all age groups, from $71 \%$ of responses among teenagers up to $95 \%$ in an older group.

Using the materials of the performed study we do not have the ability to judge what values should be present. We also can not say that the request for the evaluative nature of literature content is increased as they grow older, because nobody knows what modern teenagers will think about it, because they still need to understand what human values are and to understand the structure of the world based on these values, but we clearly see the fact of relation between age and value expectations from reading.

It is clear that when the issue of resistance to reading catastrophe and the strategies of mass interest return to reading is being solved, it is important to disclose its value aspects, and respond to doubts about the necessity of its valuable content, at which $15 \%$ to $20 \%$ of the respondents point in our sampling. It is possible that, when mostly entertainment and fun is wanted from a book, they are afraid of some regulations and restrictions that set additional social and pedagogical problems in respect of culture and society.

This assumption rests on a substantial basis. Value expectations among the respondents are not directed for the search of ideal samples. A series of the questionnaire questions deals with this particular aspect of the matter and comes from the students, that is, it was born among the youth. These are the issues about morality - the urgent issues of modern society in the context of literature and reading as the basic instruments of culture. The following firmly put questions were answered firmly by the respondents. «Should a book teach moral behavior only?»definite «no» answer $62 \%$ from the sample in general, and «Can a protagonist commit immoral acts and still be an attractive one?» - definite «yes» answer $42 \%$ and $71 \%$ with the variant «most likely yes».

One of our coauthors, the 3rd course student provides the following speculations:

- There is the idea that "a man expresses himself in his actions». But often favorite book heroes, whom we sympathize, make quite dubious actions, sometimes even immoral ones. A friend of mine answered the following to the following question: "Would you still like the hero who committed an immoral act?» - «Yes, yes and yes. On the contrary, I would stop like a book where a hero always does only right things. It ceases to be alive». In fact, there is something to think about. Actually, this question was asked for Book Fair visitors. One may speculate on this topic continuously, but many examples speak for themselves and confirm our statistics. Pechorin, who moved so many hearts and changed the lives of many ones, reflects, in fact, his generation disease the attraction of vice, committing immoral acts, one by one, but remaining to be loved by readers.

But it is not enough to state the attractiveness of a vice. We still have to understand why this thing happens. Why Grigory Pechorin is loved by readers or just by female readers? Why people like a ladykiller, a cheater, a manipulator and, in the end, a murderer? Is it because he is a good-looking, a romantic and a demonic one? Is it because he suffers from his futility in this world? Postmodern epoch easily accepts the promiscuity in matters of good and evil, the confusion, the absence of distinction between good and evil, but we see too well the devastating effects of this moral relativism, just to pass by an explicit socio-ethical fact (Fig. 2). 


\section{Признание привлекательности героя, совершающего аморальные поступки}

\% от числа опрошенных в возрастных группах

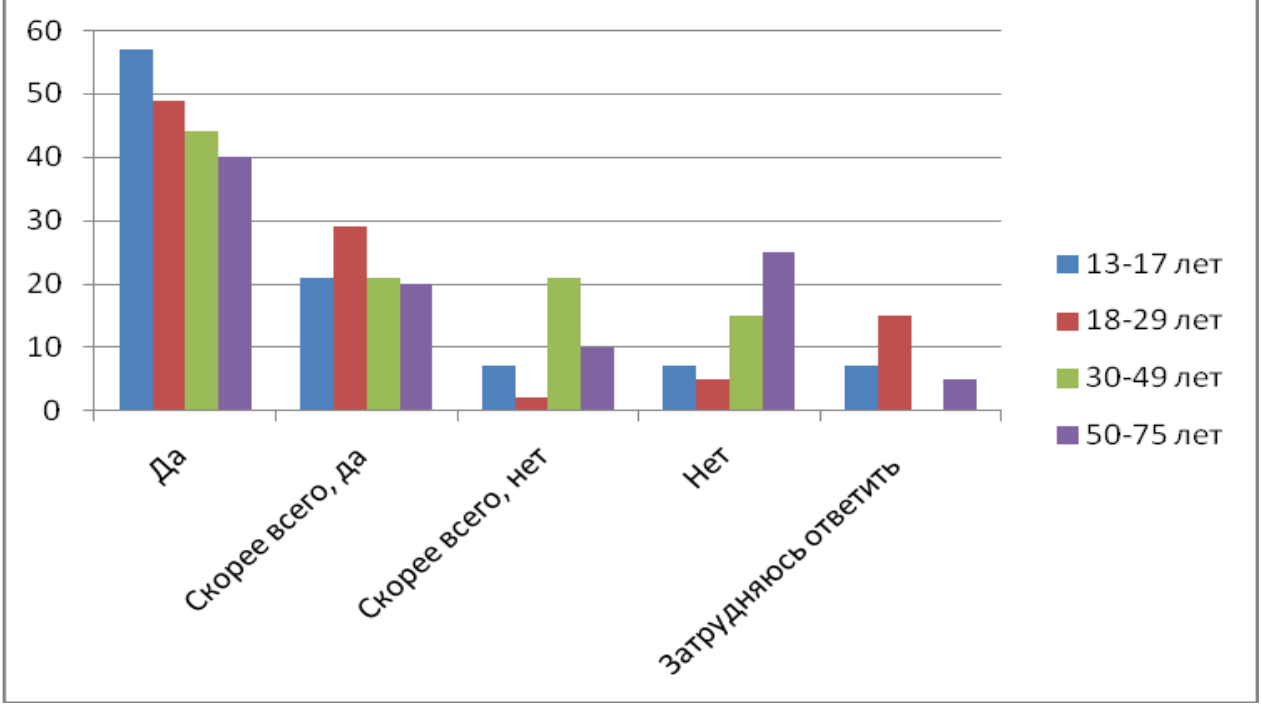

The acceptance of hero's attractiveness committing immoral acts $\%$ from the amount of interviewed in age groups

Yes, more likely yes, rather no, no, it is difficult to answer

Fig. 2.The dependence on the respondent's age of sympathy for "negative character» hero

We have to admit that there is a considerable number of issues, addressing further studies to fundamental science in the context of the set problem:

- What is articulated in the reception of literary meanings, and what is passed unnoticed, i.e., censored by personal and cultural unconscious?

- What are in these estimates from the understanding of a human nature complexity and what just from the learned facts for an exam and not enough cognized school lessons?

- What things are from already familiar and paradoxical primitive statement of the world complexity and what from the postmodern destruction of criteria, the refusal from a clear distinction between good and evil?

- What is from an increased psychological literacy of people and the reflection of one's own ambiguous experience and what is from Manichaeism peculiar for Russian culture, approved the attitude towards the ambivalence of good and evil long before postmodernism? [14].

Anyway, we see that the readers of all age groups tend to the negation of rigid moral statements and the understanding of human behavior unambiguous interpretation impossibility. This class of ratings also has the answers to one another difficult question, the discussions of which do not cease: «In what extent the information about an author's personality affect the perception of his works?» In this case, the age differences are clearly seen in study materials. The least demanding and the most tolerant to a possible "personal approach» is an average age group, the so-called «young adults» (3049 years), senior group respondents are full of rigor, and they, according to their interest in the biographical literature (see. above) are aware of emerging problems in this regard.

However, the very difference of positions in the given issue suggests a specific cognitive operation of a reader. After all, if we know more about an author's identity besides his picture on the cover and biographical data in Wikipedia, and sometimes a lot of controversial facts is known (errors, failures, fluctuations in world outlook, relations with authorities, sickness, morality), and at that it is possible to evaluate the texts of his writings and their semantic world, this indicates as a rule a high level of a reader's literacy and reading culture, associated with the ability of a reflexive attitude towards reading 
and the distinguishing of a writer's status and his positions as a real person, his author's incarnation, and the incarnations of heroes, the characters of his books as the embodiments of the author's creative demiurge abilities.

Moreover, the acquaintance with the authors, which becomes available due to their readiness for communication in social networks and at the meetings of various formats, may arouse previously implicit feelings in a reader, form and strengthen empathy, make him talk by more emotional language, incite to acts, not planned in advance. Here is an example of the personal correspondence with one of this article authors with his former graduate student, now candidate of cultural science A.O. Marova (then according to the text):

«... At the exit from Staraya Ladoga fortress, I noticed a book that is sold in a museum complex on all shelves, and, in particular, in the temple. This is B.G. Vasiliev's book «The monumental Staraya Ladoga painting of the XII-th century». I know this man I remember him, I remember his look, full of some inescapable melancholy, when he talked about the reconstruction works with whipped frescoes from George. When he talked, I had the feeling that he tells about his children, who had suffered a cruel tragedy, and he helps them to recover from some serious surgery .... These frescoes are his children ... he gathered them from the particles the diameter of which made sometimes 3-4 $\mathrm{cm}$... He gathered everything that could be gathered ... He restored it... It's beyond words when he talked about it, he emanated love and selfless dedication to this thing, this temple, these paintings ... and it was worth it. The things he did were great to me. And I felt a wild dull anger, powerlessness, helplessness, because that I did not take cash from my card due to some idiotic coincidence. The most lousy thing is that I had money! But, I could not spend it to buy this book. Not so much to read it, although it is worth reading, but because of its illustrations which are stunning ... Anyway, it's a good book, a nice one, this is the result of all author's life. A pile of his articles and studies is collected, all in one place. I felt an urgent need, not so much to buy and read it, but to buy and pay tribute to him for his great work ...»! .

Everything said above about the readers' preferences, expectations, estimates and values makes the context of the answer to the main research issue.

Books which changed us. First of all, the vast majority of respondents in all age groups agreed that a book and reading may not only give some new

1 Elena Okladnikova. Author's Archive, 2015, St. Petersburg. knowledge and experience for a person, but also to change something significant in him and his life. In total by sample, this was the answer of $97 \%$ of respondents and $100 \%$ within the teenage and older group. Regarding the period of life when this may happen, the respondents have also a general idea at any age $(70 \%$ in total according to the sample, $95 \%$ in the older group and about $65 \%$ in other groups). Along with this: the fact that it may occur mainly in childhood is stated by children (14\%) and the representatives of their parents $(9 \%)$. Another period for the compliance with such changes is considered to be the period of youth (15$30 \%$ of responses in different groups). It is noteworthy that the senior group, for which the youth is over, does not prevent the ability to change under the influence of a book. This group just shifts its assessment in the category of «all ages», choosing it in $95 \%$ of cases. In other words, the readers confirm a person's ability to change under the influence of strong cultural stimuli and senses.

Unfortunately, the scope of the project did not allow to develop it as a whole within a quality strategy and perform the series of profound interviews about this change in practice. But one may use other people's testimonies for its reconstruction. For example:

- «Pippi Longstocking» was for me some kind of a textbook concerning the liberties of the sixties, a role model... Pippi is imperturbable, true and spontaneous, and besides she has a horse. She is not afraid of exams, bandits or a shipwreck. This is a book about the methods of actions and at the same time the appreciation of your loneliness...» ${ }^{2}$.

- First, I just put down sources and literature from the poet's Diary out of interest, then I aimed to read and study them all, then I went to the archives, and finally an amateurish hobby turned into a permanent interest in the subject and became the part of the profession ${ }^{3}$.

- «Kolyma Tales» written by Varlam Shalamov is one of the books I read in 1988-1989 (together with "Master and Margarita», "White robes», «Private Chonkin», "Whirlwind tour») which changed my Komsomol student outlook forever. Now I will never be able to understand the compatriots, glorifying Stalin and his regime...»".

After making sure that the very fact of change for something real in a person and a reader's life under the influence of the books can really exist and

2

http://www.wonderzine.com/wonderzine/life/bookshelf/2147 93-plungyan (date of access: October 13, 2015).

${ }^{3}$ Ibid.

${ }^{4} \mathrm{http} / / /$ takiedela.ru/2015/06/shalamov/ (date of access: October 13, 2015). 
our question is not just a mere speculation, we are ready to continue to provide the results of the responses to an open question in the questionnaire: «Can you name a book (an author, a genre, a series of books), which will change your future life?» 98 people responded to this question, and they created a list of authors and works by their answers, including more than 75 books, and only some of them are named 2-3 times. It seems that we are witnessing the fact of almost complete uniqueness of the system affecting literary contacts. Here is a full list which is given in an alphabetical order. author)

1. «War through the eyes of children» (no

2. «Easy Way to Stop Smoking» (no author)

3. Alexander Belyaev

4. Alexander Solzhenitsyn, «Gulag Archipelago»

5. Alexander Fadeev, «Young Guard» (according to respondent Sholokhov)

6. Alexander Brushteyn, «The road goes into the distance»»

7. Alexei Tolstoy, «Buratino»

8. Alfred Kokh

9. Anatoly Kuznetsov, «Babi Yar»

10.Network literature anthology Prince»

11.Antoine de Saint-Exupery «The Little

12.Bernard Werber, «Ants»

13.Bible (5)

14.Vadim Zeland «The space of options»

15.Valentin Rasputin, «Deadline»

16.Valentina Oseeva, «Dinka»

17.Vasily Grossman, «Life and Fate»

18. Veniamin Kaverin «Two Captains»

19.Vladimir Nabokov, «Lolita»

20.Gayle Forman, «If I stay»

21.Hermann Hesse «Steppenwolf»

22.Guy de Maupassant

23.James Oliver Curwood, «The Valley of silent giants»

24.Jane Austen, «Reasons of mind»

25. Jack London, «White Fang», «Martin Eden» (2)

26.Joanne Harris, «Chocolate», «Candy shoes», «Peaches for monsieur cure»

27.John Green, «Blame stars»

28.Jonathan SafranFoer, «Extremely loud and incredibly close»

29.George Orwell, «Misfortunes in Paris and London»

30.Dina Rubina

31.Yevgeniya Ilyina, «The Fourth Height»

32.Evdokia Luchezarnova (4), all books, «Living books» (3) «There is nothing accidental in this world», «The rhythms of a new century»
33.Jean-Christophe Grange, Detectives

34.Ivan Turgenev «Fathers and Sons»

35.Clive Staples Lewis, «The Chronicles of Narnia»

36. Classics of XIX-XX centuries

37.Leo Tolstoy (2), «Resurrection»

38.Lyudmila Ulitskaya

39.Lucy Montgomery, «Ann from green mezzanines»

40.Mariam Petrosyan, «The house in where»

41.Maria Parr, «Waffle Heart»

42. Mark Twain

43.Milan Kundera «The unbearable lightness of being»

44. Mikhail Bulgakov, «Master and Margarita» (2)

45.Mikhail Lermontov (2), «Hero of our time»

46. Mikhail Sholokhov «Quiet Don»

47.Nick Vuychich «Life without Borders»

48.Nicholas Sparks, «The Notebook»

49. Olesya Duplyakina, «The ways of becoming a desirable bride»

50.Osho (Rajneesh) «Empty Boat»

51.Pamela Travers, «Mary Poppins»

52.Patrick Ness «Monster's voice»

53. Richard Bach «Jonathan Livingston Seagull» (2)

54.Robert Sheckley

55.Roland Barth, «Paris Nights»

56. Rhonda Bern, «Secret»

57.Ray Bradbury, «Dandelion Wine» (2)

58.Salvador Dali, «Diary of a genius»

59.Sebastian Faulks, «And the birds were singing»

60. Sergei Dovlatov

61. Stace Kramer, «50 days before my suicide» (2)

62.Stephen Hawking, «Stephen Hawking's

Universe»

63.Tatiana N. Mikushina, «The Word of

Wisdom». Books (2)

64.William Burroughs «Only breakfast»

65.William Golding, «Lord of the Flies»

66.Fyodor Dostoevsky (2)

67.Franz Kafka, «The Metamorphosis»

68.Frederic Beigbeder, «99 francs»

69. Haled Hosseyni, Prose

70.Haruki Murakami «Norwegian Wood»

71. Shakespeare (2), «Hamlet»

72.Sharon Draper, «Hey, let's talk»

73.Elizabeth Gilbert, «Eat. Pray. Be in love»

74.Eric Berne, «Games people play»

75.Erich Maria Remarque (2), «Arc de Triomphe»

76.Julia Gippenreiter (2), «How to deal with a baby?», «Psychology for parents»; All books 
And here are the answers to the question about a book that changed their lives from teenagers (13-17 years old, 14 people listed by alphabetical order):

1) Alexandra Brushteyn, «The road which goes into the distance»

2) Valentine Oseeva, «Dinka»

3) Gayle Forman, «If I stay»

4) John Green, «Blame stars»

5) Mariam Petrosyan, «The house where»

6) Nicholas Sparks, «The Notebook»

7) Patrick Ness, «The mopnster's voice»

8) Ray Bradbury, «Dandelion Wine»

9) Steys Kramer, «50 days before my suicide» (2)

10) Sharon Draper, «Hey, let's talk»

11) I can not tell, there was no such a book, such a book was not written yet -4 people.

12) 3 men did not answer.

Two books of this list are from Soviet children's classics (A. Brushteyn and V. Oseeva), one is the masterpiece of foreign and now classic literature (R. Bradbury), and the other works are the works of modern, mostly foreign, writers and adults have little knowledge about these books. Meanwhile, teenagers know them are call them as a very important events for themselves. What are these books about? They are often about death, always about love, childhood fears and their overcoming, about the fact that people are not only good or bad ones. One can hardly argue with the fact that it is very important for maturing children, as well as with the fact that in most cases a family and a school are not able to talk about it with their kids.

Here are some excerpts from the reviews to these books found at LiveLib.ru, which recommends itself as the largest collection of reviews in Runet and the place of readers' communication ${ }^{1}$.

Alexandra Brushteyn, «The road which goes into the distance»:

- This is a good book. Children ask questions and do not get answers. Dad teaches one thing, an invited teacher teaches other thing. Children understand everything by themselves. Who is better: «our» God and "your» God? Why can I not believe in my god only due to the fact that I live in your country? Stealing is a bad act. Is it good to let your child die of hunger without stealing any loaf of bread? ... My head is spinning, I do not want to stumble, it is necessary to look around, to turn your head and look for some answers where not a word was uttered ...

Valentina Oseeva, «Dinka»:

${ }^{1}$ Advisory service LiveLib.ru: http://www.livelib.ru/ (date of access: October 13, 2015).
- First of all, the main character is a girl! And she is not some kind of right crammer or a mannered damsel. Oh no! This is a girl, who will last for five boys! She is a shaggy imp, an unauthorized rebel, brave, cocky, restless one! Secondly, it is an amazing story about a child's friendship. Such a friendship that not every adult can boast.

- I really liked mom Marina! She is an ideal mother and I read it more than with an adult point of view, the way I would have raised my children. She studied patience and understanding from Marina.

Patrick Ness «The monster's voice»:

- This book is terrible in its honesty and openness concerning the raised issues, but it is necessary and important for all age groups. We are not taught to deal with similar situations and respond to them. Faced with such things, many get lost and do not know what to do, what to say. This book is a frank conversation about the disease and death <...> and that it is very important to talk about it.

- It is for your pleasure, right to the point, for the soul.

- It is a surprising, wildly emotional book, when you will use lots of handkerchiefs during reading. I write these lines, and the words from this book appear in front of my inner look again and again, making up sentences, images and something real. And tears veil my eyes again.

Stace Kramer, «50 days before my suicide»

- This book is the reflection of almost every teenager! It seems that your problems are worse than the problems of others! But it is not so! We all have problems and we need to live on and do not run away from them, but solve them! When I read, I thought that I had some problems, but compared to the others, these problems are pure nonsense!

\section{John Green, «Blame stars»}

- You should read the "Blame stars», if you are troubled by the fact that your life is over, because you had «B» after the exam and a handsome young man does not respond to your message at vk.com, if you are under 18 years, if you want to place everything in your life to a right place in terms of experiences and excitement because of little things (i.e. to destroy the very fact of such experiences).

- The book made me cry, although the word "cry» is quite an understatement. And it was very difficult to finish the story. And then you sit there like a squeezed lemon, and you do not know what to do next, you try to get back to reality and you can't.

\section{Ray Bradbury, «Dandelion Wine»}

- It seems when I closed the book, the switch, responsible for emotional balance, has turned inside 
me. It amused me, encouraged me, healed me. It made so that my eyes were sparkling for a long time. Such books should be taken to a desert island, to space and to underwater stations.

\section{Sharon Draper, «Hey, let's talk»}

- This is the book about Melody who miraculously causes no pity but respect for the main character. The book is written in the first person, and it makes not a usual embarrassment which we are used to experience when we deal with disabled persons ... but the admiration of her inner strength, the depth of her mind and the awkwardness from the minor problems we are busy actually most of the time, how little we notice and how poorly we understand other people.

- I really liked the book, because due to we will understand these people a little better, and quite possible it will be enough to hear them.

The reviews (and there are hundreds of them online) may be studied like narratives - texts, literature impact evidence on a reader, on the emotional sphere of communication with literature. Often they have some reports about tears («crying, sobbing», «ruined hundred of handkerchiefs»). Of course, in the vast majority of cases these are girls and women. But, apparently, it is important and necessary to show their empathy in this manner. In regard of teens, and probably not only them, you may find that in the very "feelings», the feeling of your emotions, the extension of their range beyond their own experience or the proof of your own experience is a great reading value today when stiffness and even an aggressive behavior becomes an emotional dominant. However, you may find the fact that empathy exists only in a book virtuality, whereas real life makes to exercise hardness and deafness to the problems of other people. All this is also the subject for an in-depth research.

"Influencing reading». What is the phenomenon with which we are faced in a seemingly simple survey? Let's call it «influencing reading» and let's try describe it.

Referring to the content of read sources and reading experience, we immerse in the world of semiosphere [11] - culture, understood as the field of senses, symbols, signs and meanings, which in the form of different kinds of texts, - verbal and nonverbal ones, - the creation, representation, symbolization, interpretation and transformation of subject and phenomenal world of culture semantics. A responsible man is placed in this world by his destiny and our question, and the transformation of properties and meanings takes place in the course of communication with semiosphere in general and with a book in particular.

A man reads ... What is the understanding of not these words, but the essence of the things which happen? Let's assume that a person is not an abstract actor, but a feeling, reflective person with some proto reflection at least and let's define «reading» as an operation of communication between a person and a particular section of semiosphere, which is represented by some text. What does a man «read» in it? According to academic coercion he reads something that «should» be read, in the best case this is the fact «that an author wanted to say», and for their own purposes and motives these are the things that we manage to catch, like on a hook, responding to our requests in accordance with our dominants. He «reads» from a text the things which are consonant with these requests, dominants, personal «matrices», sets, neurosemiotics [see: 7], nonverbal semiotics [see: 8], «an embodied mind» [see: 10] - those nervous, brain, bodily, and, as a result, cognitive mechanisms that allow us to feel and move, and which also generate our conceptual structures and the ways of thinking [see also the following research works: $1 ; 2 ; 5 ; 12]$.

A connecting thread, a capillary, through which the nutritional and educational substance flows, is drawn between a person, his brain and a book. There is an attraction, a connection, the feeling of identity, an explicit or implicit self match is achieved self with a «message», a text message or the thing which we will consider as a message for ourselves. There is identification, a merger, an insight, a moment of love. As in «Avatar»: «I see you». Or as in one of the reviews: «Yes, this is mine, this is what I need». «It's me, the Lord» as Rockwell Kent titled his autobiography, following the words of the old Negro national anthem. This is the contact a person needs to understand his own essence and answer the questions. If we put it in a very high style - «his essence» means before God and God's meanings. A person, the subject of semantic and meaningful cultural contact has a constant completion of $\langle\mathrm{I} »\rangle$, and it happens when all is matched and put together when «I» saw himself in the mirror of a book.

But first of all an explicit or even implicit request is necessary - temporarily empty and requiring the filling in of «a holy place» in a soul and a body, disturbing rattling, membrane pulsation that haunts, an open «valence» offering the connection to someone or something and to establish a necessary, desired, an expected relation - an influencing, a crucial and an essential contact. And here we see that it is being established. This process, in fact, may take 
a lifetime. It is known that sometimes people read the same book many times, each time finding something new. Life creates new «empty spaces» in an individual neurosemiotic system, reveals new «valencies».

Does this mean $50 \%$ of the population that do not read are the people with no questions to the world? It is not excluded. And if so, then many things become clear additionally on the status of mass and public consciousness in our country, on its human potential and intellectual capital.

Almost every answer to the question about the book that changed his life, found his point of personally meaningful communication, realized his previously opened «valency». Who is Virgil here? Who is the conductor who is the «Navigator»? - A friend, a teacher, the list of «Top 100» books? - Yes, a little bit of everything. But more often a man himself is in his own search (30-40-50\% of responses in age groups) and «a god-inventor case»$15-20-30 \%$ more. That is this is mostly himself seeking an answers to their questions, the requests of his «I», eager to gain integrity, create or arrange his world of senses ...

As we mentioned already, influencing reading as the phenomenon of an individual reader's practices proved to be an extremely diverse one. It has no trends almost except for the diversity and the variability over time, correlated with the membership to a particular generation, and thus, with their referential personal and cultural situation (Table).

Leaders of the affecting reading

\begin{tabular}{|c|c|c|c|}
\hline \multirow{5}{*}{ 13-17 years } & $18-29$ years & $30-49$ vears & $50-75$ years \\
\hline & Luchezarnova E. (1) & Luchezarnova E. (4) & Luchezarnova E. (4) \\
\hline & The Bible (2) & The Bible (3) & \\
\hline & & Mikushina T. (2) & Mikushina T. \\
\hline & J. London & J. London & \\
\hline \multirow[t]{2}{*}{ Bradbury R. } & Bradbury R. & & \\
\hline & & Shakespeare & Shakespeare \\
\hline Brushteyn A.Ya. & Bart R. & Bach R. (2) & Grange J.-C. \\
\hline G. Greene. & F. Beigbeder & Belyaev A. & Kaverin V. \\
\hline Sh. Draper & Bern R. & Bulgakov M. (2) & Parr M. \\
\hline Kramer St. & Bern E. & Werber B. & Rubina D. \\
\hline Ness P. & W. Burroughs & Gippenreiter Y. (2) & Saint-Exupery A. \\
\hline Oseeva V. & N. Vujcic & V. Grossman & Solzhenitsyn A. \\
\hline Mariam Petrosyan & H. Hesse & Duplyakina O. & Mark Twain \\
\hline Sparks N. & Gilbert E. & Zeland V. & Ulitskaya L. \\
\hline \multirow[t]{20}{*}{ G. Foreman } & W. Golding & Ilina E. & A. Fadeev \\
\hline & S. Dali & J. Curwood & Hosseini H. \\
\hline & Dovlatov S. & A. Koch & \\
\hline & F. M. Dostoevsky (2) & M. Lermontov & \\
\hline & F. Kafka & Lewis K. & \\
\hline & Kuznetsov An. & Montgomery L. & \\
\hline & Kundera M. & Maupassant G. & \\
\hline & M. Lermontov & E.M. Remarque (2) & \\
\hline & Murakami H. & Tolstoy A. & \\
\hline & Nabokov V. & Turgenev I. & \\
\hline & Orwell G. & Shekly R. & \\
\hline & Austin G. & Sholokhov M. & \\
\hline & Osho (Rajneesh) & & \\
\hline & Rasputin V. & & \\
\hline & L. Tolstoy & & \\
\hline & Travers P. & & \\
\hline & Foer D.S. & & \\
\hline & Foulkes S. & & \\
\hline & Harris G. & & \\
\hline & Hawking S. & & \\
\hline
\end{tabular}

Table 
Except for a very small similarities in names and authors an influencing reading space is highly diverse in genres and sorts of literature, according to ideas and the countries of origin. An age dynamics is inherent to it: the expansion during the periods of growth and narrowing during the periods with aging vector. Its area is fundamentally different from the mass of "general reading» area, which we learn from large surveys. Otherwise, we would have received an obviously stereotyped and doubtful relevant listing: Pushkin, Lermontov, Yesenin, «Tolstoevsky» ... At the same time, with all the differences in size, even our small sample catches some common grounds with the results of large projects and allows us to speak about them as about modern constants:

- a high proportion of foreign literature in the structure of reading among those for whom this is an ordinary way of life;

- little interest in poetry;

- some plaque of an elitist snobbery on the part of literary-based community;

- and a clear segmentation of a reading space, dividing it into groups, quite isolated from each other in culture.

These common features of different research allow us to think that in our case we are not dealing with an artifact, but with some stable characteristics of a modern reader phenomenon, and that the obtained data can be used for its conceptualization.

Modifying effects of influencing reading. What changes were noticed by our respondents when they were reading the books they named? The responses have filled all the space of the proposed survey scale (although quite a generalized one), and the made additions were irrelevant ones. According to respondents, it is mainly a worldview, a position $-46 \%$ of responses in total according to the sample, the understanding of people makes $42 \%$, the knowledge about the world, society and a man makes $30 \%$ and the relation of their country makes $12 \%$ of the responses.

The group characteristics of influencing reading effects are also clearly visible. Let's note their main accents. A pronounced accent, the dominant of the whole system of influences is the position value concerning people's understanding for the teenage group $-64 \%$ of its population and $86 \%$ of those who answered the question about the presence of the book which influenced them heavily. During adolescence, the vast majority of people develop a social intelligence, the most important elements of which are communication skills, social perception, social thinking and imagination, social forecasting, empathy, intuition and regulation, i.e., everything that is taught by the books mentioned by our teenage respondents as the books that changed their lives. That's why the obtained result, in our view, is the evidence of a high need of adolescents in the development of a person's diversity world and at the same time a sensitive strongest hunger in this regard with a weak possibility to satisfy it.

Another notable trend is the growth of ideological influence of books, and hence the interest to this level of knowledge during the maturation. The older group is focused (compared with other elements) on a more clearly expressed (probably reflective) request for a generalized vision of society and the relationship to the country as a whole.

Some deviations of influencing reading. In the present structure of preferences (Table. 1) one dominant name draws its attention. It is put in the «top» by the supporters of quite popular «teaching» (we will not name it once again) about the possibilities of «a person operation with time» enabling «accelerate, stretch, slow down time and also move in time to the past or to the future». The author of this teaching, her real name and her expressive nicknames were mentioned by the respondents with an exceptional reverence, with a deep conviction that the meeting with her books, radically changed their lives indeed. The message of meant works was actually promising: "When you come to me, you will get extra time and go with it in your previous life with a full, easy, renewed brain. And 〈these my-O.K.> books will help you» ${ }^{l}$.

Some may consider such allegations as a pretentious manipulation, but there is an a priori confidence in informants in a cognitive attitude of our project, and when they repeatedly refer to these books in the context of life changes, and indicate on their impressive influence in the questionnaires («everything has changed»), - therefore, we must state the effectiveness of these creations, and, as it turns out, a broad missionary activity of their author ${ }^{2}$. The admirers of the teaching are usually the representatives of the older age groups, and the Fair had a lot of visitors among them. Well this may be a good thing, if people have some new and positive thoughts during the second half of their lives. They formed something like a nationwide and even an international club, perhaps even a sub-culture club that allows us to solve some of our problems, to find like-minded people, to enter the network of interesting communication, etc.

It was not the only event of this kind at the Fair. Even our small sample had almost $8 \%$ of this subculture adherents, and together with the

http://yevdokiyamarchenko.com/kak-ya-rabotayu-slyudmi/ (date of access: October 13, 2015).

${ }^{2}$ The Institute, established by the author, has the status of a "public institution", has the sense, gravitating to the teachings of the "New Era (New Age»). Wikipedia calls it directly destructive sect. See also: http://www.kistine.ru/sects/radasteia/radasteia.htm (date of access: October 13, 2015). 
supporters of other wisdom sources, such as «the teachings of the ascended masters» in the violet flame, putting down their «dictations» to people through «messengers», etc. - there are more of them, and the name of such a wisdom conductor is in the submitted lists too.

Of course, it is the sampling fluctuation to a large extent that is not a serious error for our purposes, because the impact phenomenon is confidently confirmed by this. But at the same time this is the testimony of a fairly broad presence at the prestigious International Book Fair of all sorts of marginal literature and its active distributors, to which journalists covering its work paid their attention ${ }^{1}$.

Developmental reading effects. The vast majority of respondents (88-94\% in different age groups) prefer a printed book to the rest of its current hypostases - an electronic, audio, online one. It's quite an unexpected result when you consider the trend for gadgets, an expensive cost of books, a small range of books in a bookshop within regions, the weakening of library network and the challenges of their set completing. Perhaps the reason of it is that the Fair participants are the amateurs of reading and the book professionals, and random people could see that it is festive and elegant, beautiful and emotionally valuable when one may leaf through a book, see illustrations, hold a work of art in one's hands, the fruit of a human labor, not a mathematical program. Maybe that's why the majority of respondents believe that it is possible and necessary to make reading a fashionable occupation, especially if the community is concerned to bring back the interest in reading among everyday behavioral practices (stable 70-75\% of responses in all groups). According to them it is not an allegation for the demonstration of their «cultural level», people explain their position by the fact that they see a fundamental difference between reading as an intellectual work with a text and its listening or screen version.

Why do you need people read it, but not receive information in other ways, that in our days is quite possible and not reprehensible? Even psychologists believe that the so-called «clip thinking» is an inevitable consequence of civilization development and it is an acceptable means of reality perception and decision-making. After all, in the era of high technology, information density and speed the ability

\footnotetext{
${ }^{1}$ See, for example, Mokhova S. Salon of wartime [Online] http://www.rosbalt.ru/piter/2015/05/25/1401371.html (date of access: October 13, 2015).
}

to see a situation «picture» as a whole, without any need for long descriptions and explanations, and quick making of necessary decisions is a great advantage.

In some activities and in certain situations it is true. But people with a clip thinking, capable of fast and accurate «grasp» of individual situation «frames», do not notice often their context, have a poor systemic vision, systematic discourse, an indepth analysis, and therefore think in a simple and a chaotic way. They may win in tactics, but they will lose in strategy. They do not relate different manifestations of a complex whole to each other and, ultimately, they are manipulated easily. Such thinking can not cope with the need to «practice complexity» (Merab Mamardashvili) - to understand it, to explain it, to solve its peculiar global problems. Psychologists, linguists, and other representatives of the humanities talk increasingly about the fact that the gap between literate minority and illiterate majority is based precisely on the ability to conceptual, verbal and logical thinking, the loss of which threatens the degradation of everything that was brought by civilization.

Here is an interview with the linguist, Professor G. Guseinov, who responds to a reporter's question about the difficulties of everyday communication, where a simple oral speech becomes a stress. In particular, let's add that it is also takes place in educational communication, for the students who speak or write poorly: «Every now and then I come across people who write and fine and speak clearly and expressively. Where do these people come from? They just read a lot, both in paper and in a digital form. They exchange the opinions about the books they read with their own kind, they know two, three or four foreign languages, travel along world and relate what they saw and heard with their own experience. At that they do it in writing. But there are less such people than uneducated TV viewers» [13].

Reading is one of the simplest and most affordable ways of conceptual thinking development, as the experts and readers tell us. He is like some kind of intellectual work necessary for learning and self-knowledge as the means of a person and thinking development - it is impossible to substitute it. Recognizing the relevance and prospects for new forms of reality representation, including clip ones, we must replenish and balance the bias in the development processes, which is brought by the variety and an impressive strength of new reception and communication resources with the external (and internal!) world. Good old reading will help us here. 
Summary. It seems that the small (according to scale and the number of respondents) project «Books that changed us», may take its own place among the vast studies of reading problem, as it is focused not on massive, but on the contrary, on specific, even elite forms, as long as reading is associated with elitism today [see, for example: $3 ; 6$ ]. Here are some results and the questions are raised worthy of further study.

Our small sample still caught some constants with the results of large sociological research projects in the field of reading sociology. Among these sustainable products one may name the following ones: a high proportion of foreign literature in reading structure of those for whom this is a common way of life; poor interest in poetry on this background; some touch of an elitist snobbery on the part of literary-based community; as well as a clear segmentation of reading space, dividing it into groups, quite isolated from each other in culture.

Another important result of the study is the revealed recognition of an ambiguous character by a reader. Our informants had a peculiar denial of rigid moral precepts and the understanding of unambiguous interpretation of human action impossibility, suggesting the change of black and white value orientations of moral consciousness by relativistic type values.

The phenomenon of «influencing reading» is reported and conceptually represented. Most of the respondents recognized it for himself and found it possible to report what aspects of their lives were influenced by a book. They also demonstrated a good understanding of developmental reading effect and formulated a lot of qualified positions in this regard.

A high level of literary work diversity is revealed, which influenced some circumstances of life among the respondents. These circumstances were important concepts for them. This list does not show any trends except for diversity and the variability in time.

Despite the fact that the surveys register some cooling of the Russian population to reading, we obtained the results suggesting that the audience will not lose interest to a paper book soon and also the results about meaningful, developing reading which brings up some ideas. The interest in reading is an obstacle on the way to a mass practice development concerning «clip thinking» that does not allow a person to think logically and consistently.

During the penultimate day of the International Book Fair work the presentation of research results took place. The students of the Department of Sociology (Herzen University) presented the obtained data to the public, causing the interest of Fair visitors not only concerning the work theme, but also its results.

The authors thank the librarian of the Library named after V. V. Mayakovsky Stanislav Vyacheslavovich Stepanov for the help in the organization and support of the project.

\section{References}

1) Birkerts, S. The Gutenberg Elegies: The Fate of Reading in an Electronic Age. Boston; L.: Faber \& Faber, 1994. $231 \mathrm{p}$.

2) Brockmeier, J., Wang, M. and Olson, D. R. Literacy, Narrative, and Culture. Richmond, UK: Curzon, 2002. vi, 314 p.

3) Donald, S. and Leeds, Ed. D. Sociology of Reading: Social and Cultural Factors. Reading World. Vol. 13. Issue 4. (1974). Pp. 318-333. [Online] URL: http://www.jstor.org/stable/27536640 (date of access: November 4, 2015).

4) Dubin, B. V. and Zorkaya, N. A. Reading in Russia - 2008. Trends and Issues. Moscow: Interregional center for library cooperation, 2008. $80 \mathrm{p}$.

5) Griswold, W. and Wright, N. Wired and Well Read. Society Online: The Internet in Context / Ed. P.N. Howard and S. Jones. Thousand Oaks, CA: Sage, 2004. Pp. 203-222.

6) Griswold, W., McDonnell, T. and Wright, N. Reading and the Reading Class in the Twenty-First Century. Annual Review of Sociology. Vol. 31 (2005). Pp. 127-41. doi: 10.1146/annurev.soc.31.041304.122312.

7) Ivanov, Vyacheslav Vs. Selected Papers on Semiotics and the History of Culture. Vol. I. Semiotic Systems. Cinema. Poetics. Moscow: Yazyki russkoi kultury, 1998. $912 \mathrm{p}$.

8) Kreydlin, G. E. Non-verbal Semiotics: Body Language and Natural Language. Moscow: Novoe literaturnoe obozrenie, 2002. $581 \mathrm{p}$.

9) Lakoff, G. and Johnson, M. Metaphors We Live. Moscow: URSS Editorial, 2004. 256 p.

10) Lakoff, G. and Nunez, R. The Origin of Mathematics: the Creation of Mathematics by a Real Mind. Horizons of Cognitive Psychology. Moscow: Yazyki slavyanskikh kultur; Moscow: RSHU, 2012. Pp. 29-48.

11) Lotman, Yu. M. Semiosphere. St. Petersburg: Publishing house «Art-SPB», 2010.704 p.

12) Reading the Situation: Book Reading, Buying and Borrowing Habits in Britain. London: Book Marketing Ltd, 2000.

13) Ryzhova, P. Interview with Hasan Huseynov. «A new reality will come to us via a language import». Газета.ru, 08/15/2015. [Online] URL: http://www.gazeta.ru/comments/2015/08/14_a_7687912.s html (date of access: November 4, 2015).

14) Yakovenko, I. G. and Muzykantsky, A. I. Manichaeism and Gnosticism: the Cultural Codes of Russian Civilization. Moscow: Russki put', 2010. 320 p. 